\title{
Colorectal endoscopic submucosal dissection for all LSTs: histological information loss due to piecemeal EMR is no longer acceptable
}

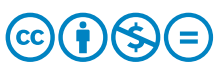

\author{
Authors \\ Mathieu Pioche ${ }^{1}$, Jérôme Rivory ${ }^{1}$, Jérémie Jacques ${ }^{2}$ \\ Institutions \\ 1 Hepatogastroenterology division, Edouard Herriot \\ Hospital, Lyon, France \\ 2 Hepatogastroenterology, Dupuytren hospital, Limoges, \\ France \\ Bibliography \\ DOI https://doi.org/10.1055/a-0982-3223 | \\ Endoscopy International Open 2019; 07: E1195-E1196 \\ (c) Georg Thieme Verlag KG Stuttgart · New York \\ eISSN 2196-9736 \\ Corresponding author \\ Mathieu Pioche, MD, PhD, Service de gastro-entérologie et \\ d'endoscopie digestive, Pavillon L, Hôpital Edouard Herriot, \\ 5 place d'Arsonval 69437, Lyon, France \\ Fax: +33472110147 \\ mathieu.pioche@chu-lyon.fr
}

Laterally spreading tumors (LSTs) are colorectal neoplastic flat or sessile lesions with lateral extension exceeding $1 \mathrm{~cm}$. This term is generally used for superficial adenomas or adenocarcinomas, but very rarely for supracentimetric sessile serrated lesions or ulcerated invasive adenocarcinomas.

There is still a very active debate in the endoscopic community about the best choice of technique for resecting superficial neoplasias with negligible risk of metastatic lymph node evolution (intramucosal or superficial submucosal adenocarcinoma without vascular or lymphatic embols, without budding and not undifferentiated). Some defend piece meal endoscopic mucosal resection (EMR), which allows the lesions to be resected in several fragments with a diathermic snare and others, including ourselves, defend endoscopic submucosal dissection (ESD), which most often allows removal of a single piece with safety margins using a dissection knife.

Endoscopic prediction of histology is far from an exact science and even Japanese experts predict only a statistical risk of invasive cancer within a lesion based on its endoscopic characteristics [ 1 - 3]. For example, this risk is almost $50 \%$ for pseudodepressed non-granular LSTs, nearly $20 \%$ for granular LSTs with a macronodule, and risk remains quite low (<3\%) for homogeneous granular LSTs without any macronodule. In addition, degeneration of LST is not at all homogeneous and there can sometimes be a very small outbreak of invasive cancer within a large lesion, most of which is adenomatous.

Because it is impossible to predict with certainty which lesion will contain invasive or noninvasive cancer, it is still essential today to choose the resection technique a priori, by assessing a benefit-risk ratio. Finally, only the report of histological analysis allows us to decide in a multidisciplinary meeting if re- section can be considered curative. However, to rely on that report, we must ensure that it is high quality, and it can only be thorough if the part has been seen in its entirety. That is, it must be in a single piece, oriented, and with lateral and deep safety margins to confirm that resection is complete. Presence of a single vascular embol in a tumor that superficially invades the submucosa is associated with a 5 to 10 times greater risk [4-6] of lymph node metastases developing. How can we still risk missing this embol in 2019 under the pretext that the best technique takes a little longer than the reference technique that cured the majority of patients?

Some argue that risk of perforation of dissection (3-5\%) [7] is higher than that for piecemeal EMR (1-3\%) [8], but that needs to be verified with the new generation who have performed more dissections than piecemeal EMR, unlike experts who authored literature a few years ago and who compared years of experience in EMR with a low experience in ESD.

In addition, can we still talk about complications when more than $95 \%$ of these perforations are closed with clips and do not lead to surgery $[9,10]$ ? These diminutive perforations have most often become adverse events without consequence; on the other hand, if an embolus, a budding or focal invasion has been missed because the fragment in question has not been recovered, there will be dramatic consequences for the patient, who will not then benefit from the complementary surgery recommended for permanent healing. Of course these situations are rare and studies to demonstrating outcomes of dissection in terms of survival would require huge numbers of people. However, ESD is now accessible outside Japan and in the colon, facilitated by traction techniques [11]. Therefore, it is no longer possible to consider the technique restricted to use in research 
by endoscopists who extremely experienced. Training centers and expertise will be soon available outside of Japan to teach European physicians to use ESD to treat large, superficial lesions of the colon. Even for a homogeneous LST-granular, in which risk does not exceed $3 \%$ [1], it does not seem possible to argue that the risk is too low to justify cutting a lesion into pieces and losing information about a pejorative histological element.

At a time when all our activity is focused on improving quality, it no longer seems possible to proceed without a quality sample for histology and the certainty of having cured the patient. How can we expose a patient to a question of cure when a specimen arrives in pieces yet we have no certainty that we have all the pieces?

In addition, risk of local recurrence is much higher after piecemeal mucosectomy [8], and as a result, the need is increased for endoscopic control to ensure that there is no recurrence. These controls are a source of stress and discomfort for the patient with repetition of colonic preparations, and unnecessary expenses for society with repeated readmissions. The medicoeconomic benefit of the strategy using ESD remains to be demonstrated in a randomized study, which the Japanese refuse to do because they won't degrade lesions through an irreversible process and thus lose information. One of these randomized studies has been planned in France (NCT03962868) but we, too, will have trouble consenting to lowering the quality of histology assessment to demonstrate once and for all that with use of piecemeal EMR, part of the histological information is lost and the need for endoscopic control is increased.

\section{Competing interests}

The authors are instructors in a program supported by Olympus for teaching ESD.

\section{References}

[1] Yamada M, Saito Y, Sakamoto T et al. Endoscopic predictors of deep submucosal invasion in colorectal laterally spreading tumors. Endoscopy 2016; 48: $456-464$

[2] Tateishi Y, Nakanishi Y, Taniguchi $\mathrm{H}$ et al. Pathological prognostic factors predicting lymph node metastasis in submucosal invasive (T1) colorectal carcinoma. Mod Pathol Off J U S Can Acad Pathol Inc 2010; 23: $1068-1072$

[3] Ikehara H, Saito Y, Matsuda T et al. Diagnosis of depth of invasion for early colorectal cancer using magnifying colonoscopy. J Gastroenterol Hepatol 2010; 25: 905-912

[4] Ogawa T, Yoshida T, Tsuruta T et al. Tumor budding is predictive of lymphatic involvement and lymph node metastases in submucosal invasive colorectal adenocarcinomas and in non-polypoid compared with polypoid growths. Scand J Gastroenterol 2009; 44: 605-614

[5] Bosch SL, Teerenstra S, de Wilt JHW et al. Predicting lymph node metastasis in PT1 colorectal cancer: a systematic review of risk factors providing rationale for therapy decisions. Endoscopy 2013; 45: 827 834

[6] Glasgow SC, Bleier JIS, Burgart L] et al. Meta-analysis of histopathological features of primary colorectal cancers that predict lymph node metastases. J Gastrointest Surg Off J Soc Surg Aliment Tract 2012; 16: $1019-1028$

[7] Saito Y, Uraoka T, Yamaguchi Y et al. A prospective, multicenter study of 1111 colorectal endoscopic submucosal dissections (with video). Gastrointest Endosc 2010; 72: 1217-1225

[8] Saito Y, Fukuzawa M, Matsuda T et al. Clinical outcome of endoscopic submucosal dissection versus endoscopic mucosal resection of large colorectal tumors as determined by curative resection. Surg Endosc 2010; 24: $343-352$

[9] Takamaru H, Saito Y, Yamada M et al. Clinical impact of endoscopic clip closure of perforations during endoscopic submucosal dissection for colorectal tumors. Gastrointest Endosc 2016; 84: 494 - 502.e1

[10] Cho SB, Lee WS, Joo YE et al. Therapeutic options for iatrogenic colon perforation: feasibility of endoscopic clip closure and predictors of the need for early surgery. Surg Endosc 2012; 26: 473 - 479

[11] Jacques ], Charissoux A, Legros R et al. Double-clip counter-traction using a rubber band is a useful and adaptive tool for colonic endoscopic submucosal dissection. Endoscopy 2018; 50: 179-181

\section{CORRECTION}

Pioche M, Rivory J, Jacques J. Colorectal endoscopic submucosal dissection for all LSTs: histological information loss due to piecemeal EMR is no longer acceptable

Endoscopy International Open 2019; 07: E1195-E1196. DOI: 10.1055/a-0982-3223

In the above mentioned article the first name and last name of an author was swapped. Correct is: Jérémie Jacques. 